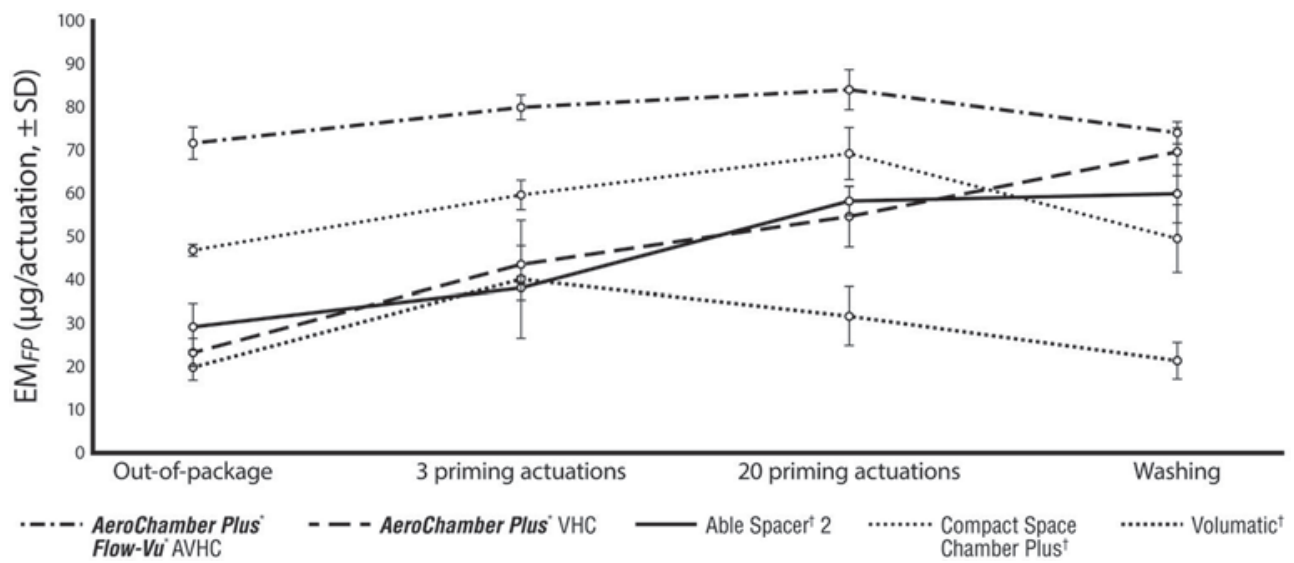

\title{
Abstract P279 Figure 1
}

(representing 3 actuations of priming).3) Deliver 17 more actuations into the same $\mathrm{VHC}$ and evaluate $\mathrm{EM}_{\mathrm{FP}}$ (representing priming of 20 actuations). 4) Clean VHC, then repeat part (1) (representing pre-conditioning by washing as an alternative to priming).

Results The behaviour of $\mathrm{EM}_{\mathrm{FP}}$ (mean $\pm \mathrm{SD}$ ) with VHC type is summarised in figure 1 .

Conclusions Clinicians should be aware that priming of VHCs Results in inconsistent medication delivery, and is wasteful of medication.

\section{P280 HOW DO WE CHOOSE INHALERS? PATIENT AND PHYSICIAN PERSPECTIVES ON ENVIRONMENTAL, FINANCIAL AND EASE-OF-USE FACTORS}

KL Liew, A Wilkinson. Lister Hospital, East and North Herts NHS Trust, London, UK

\subsection{6/thoraxjnl-2017-210983.422}

Introduction Inhaled therapy is widely used as mainstay treatment in chronic respiratory conditions, however the environmental impact of inhalers is rarely considered when prescribing inhalers. A recent BTS position statement "encourages all prescribers and patients to consider switching pMDIs to non-propellant devices whenever they are likely to be equally effective."(1) Little is known about Patients' or Physicians' perspectives on making such a switch.

Methods A survey was carried out to assess the importance of three factors to consider, if changing to a different but equally effective inhaler - cost, carbon footprint and ease-of-use. Information about the typical costs and carbon footprints of inhalers was provided. 50 patients already using regular inhalers were randomly recruited via Respiratory Clinics at a district general hospital and Pulmonary Rehabilitation sessions. Responses were rated on a 5 -point scale from not important to very important. The same survey was also completed by 50 medical professionals who regularly prescribe inhalers.

Results $80 \%$ of patients surveyed rated the ease-of-use as important or very important consideration when changing inhalers. The 'cost' and 'carbon footprint' of the inhaler were equally important to patients (3.4 out of 5); only $14 \%$ of patients indicated that carbon footprint was of no importance to them.

Abstract P280 Table 1 Comparison of the importance given by patients and physicians to consideration of cost, carbon footprint and ease-ofuse when changing inhalers

\begin{tabular}{|c|c|c|c|c|c|c|c|}
\cline { 3 - 8 } \multicolumn{2}{c|}{} & \multicolumn{2}{c|}{ Inhaler Cost } & \multicolumn{2}{c|}{ Carbon Footprint } & \multicolumn{2}{c|}{ Ease-of-use } \\
\hline $\begin{array}{c}\text { Importance } \\
\text { Ranking }\end{array}$ & Score & Patient & Physician & Patient & Physician & Patient & Physician \\
\hline Not important & 1 & $12 \%$ & $14 \%$ & $14 \%$ & $14 \%$ & $8 \%$ & $0 \%$ \\
\hline Slightly important & 2 & $8 \%$ & $8 \%$ & $8 \%$ & $18 \%$ & $0 \%$ & $2 \%$ \\
\hline $\begin{array}{c}\text { Moderately } \\
\text { important }\end{array}$ & 3 & $32 \%$ & $16 \%$ & $34 \%$ & $22 \%$ & $12 \%$ & $2 \%$ \\
\hline $\begin{array}{c}\text { Important } \\
\text { Imery important }\end{array}$ & 5 & $22 \%$ & $44 \%$ & $16 \%$ & $30 \%$ & $16 \%$ & $12 \%$ \\
\hline $\begin{array}{c}\text { Vertant \& Very } \\
\text { Important }\end{array}$ & $4 \& 5$ & $48 \%$ & $62 \%$ & $44 \%$ & $46 \%$ & $80 \%$ & $84 \%$ \\
\hline $\begin{array}{c}\text { Average (mean } \\
\text { score out of 5) }\end{array}$ & & $26 \%$ & $18 \%$ & $28 \%$ & $16 \%$ & $64 \%$ & $96 \%$ \\
\hline
\end{tabular}


Physicians rated ease-of-use even higher than patients, with $96 \%$ deeming this as an important or very important factor. Physicians rated carbon footprint slightly less importantly (3.2) than cost (3.4) and also lower than patients rated carbon footprint. $14 \%$ of physicians thought that carbon footprint was of no importance.

Conclusions Patients and Physicians agree that ease-of-use is the most important factor when choosing a new inhaler. This appears to contradict the fact that overall patients make fewer errors using DPIs(2), while the majority of inhalers prescribed in the UK are pMDIs(3). The data suggests that patients rate carbon footprint more importantly than physicians. The carbon footprint of inhalers is an important factor for the majority of patients, which should encourage physicians to discuss this consideration with patients prior to commencing or changing inhalers. 


\section{Innovation in service design}

\section{M1 ASSERTIVE OUTREACH FOR PERSISTENT FREQUENT ATTENDERS WITH COPD IN THE COMMUNITY: REDUCING ATTENDANCE BY MEETING THEIR UNMET PSYCHOLOGICAL NEEDS}

CSJ Chan, L Graham, D Roots, M Hodson, S Sunak. Homerton University Hospital NHS Foundation Trust, London, UK

\subsection{6/thoraxjnl-2017-210983.423}

Introduction and Objectives Co-morbid mental health problems in COPD can result in maladaptive and inappropriate utilisation of healthcare services (e.g., panic attacks cause attendance at $\mathrm{A}$ and $\mathrm{E}$ and acute hospital admission). Research evidence shows that COPD patients with co-morbid mental health problems have a higher rate of persistent $\mathrm{A}$ and $\mathrm{E}$ attendance and unplanned hospital admissions and on average incur an additional $80 \%-102 \%$ of medical treatment cost (Makek \& Norris, 2008). Conventional models of mental health service provisions (e.g., Improving Access to Psychological Therapies (IAPT), secondary care mental health services) have proved ineffective in accessing and treating this subgroup of COPD patients. As such, there is a financial incentive for health services to develop more person-centred and cost-effective service models to address this issue. The current study investigates the effect of an Assertive Outreach Model of psychological interventions as applied to COPD patients with histories of frequent attendances to $\mathrm{A}$ and $\mathrm{E}$ and unplanned short-term hospital admissions. Attendance behaviours, depression and anxiety symptoms, and treatment costs were investigated.

Methods 19 COPD patients with persistently high attendance behaviours (i.e., three or more $\mathrm{A}$ and $\mathrm{E}$ attendances and/or two or more unplanned hospital admissions in a 12 month period) were identified from cross-referencing data from Electronic Patients Record (EPR) and the clinical knowledge of the community COPD team. They were then proactively engaged in an assertive outreach model within two weeks of identification, and offered four to 12 sessions of communitybased psychological intervention during a 24 month period.

Results Compared to their 12 month pre- psychological intervention baseline, a total reduction of $40 \%(n=56)$ A and $E$ attendances and 33\% $(\mathrm{n}=32)$ short-term inpatient admissions was seen which amounts to approximately $£ 30000$ of cost savings on treatment per year. $16 \%(n=6)$ and $21 \%(n=8)$ of patients reported a significant reduction in their depression and anxiety.

Conclusions An Assertive Outreach model of psychological intervention for COPD and co-morbid mental health problems providing responsive community-based treatment is highly effective in reducing attendance behaviours, achieving cost-savings, and by implication improving quality of life. However, it does not significantly improve patients' mental health symptoms which is likely due to the complex and multiple needs of this patient group.

\section{M2 ADULT INTEGRATED RESPIRATORY CARE; STAFFING, POPULATIONS SERVED AND PATHWAYS OF CARE IN THE UK IN 2017}

KL Redden-Rowley, LJ Restrick, L Preston. British Thoracic Society Models of Care Committee, London, UK

\subsection{6/thoraxjnl-2017-210983.424}

Introduction and objectives NHS England has defined integrated care as services that are patient centred, coordinated and tailored to the needs and preferences of the individual, their carers and family. An integrated care service also is one that has moved away from episodic care to a more holistic approach to health. The aims of the British Thoracic Society (BTS) Models of Care Committee (MoCC) are to identify current integrated respiratory services, gain a better understanding of the models and components of integrated respiratory care and to share learning.

Methods An electronic survey was designed to determine workforce involvement, populations served and interventions offered by respiratory integrated services. This was emailed directly to all BTS members and via a link to Primary Care Respiratory Society-UK, Association of Chartered Physiotherapists in Respiratory Care and Association of Respiratory Nurse Specialists members.

Results 113 clinicians participated in the survey: 64 nurses, 29 consultants, 14 physiotherapists and 6 others. 59/113 (52\%) reported working in an integrated service.

44 adult integrated respiratory care services were identified: Scotland (1), Northern Ireland (2), North of England (10), Midlands/East of England (12), London (10), South of England (9).

- $75 \%$ teams were consultant-led, 54\% nurse-led and $27 \%$ physiotherapist-led

- All teams included nurses, 93\% physiotherapists and 90\% consultants

- $95 \%$ accepted patients with COPD, 72\% bronchiectasis, $68 \%$ asthma, 61\% interstitial lung disease

- A wide range of services were offered; see Table 1

- 65\% described care co-ordination involving primary, secondary and community care

- $45 \%$ reported using a shared care record

- $50 \%$ offered a 7 day service.

Conclusion With at least 44 services across the UK in 2017, adult integrated respiratory care is already an established model of care, in particular, but not only for COPD in the UK. Leadership and delivery is largely by a respiratory nurse specialist, physiotherapist and consultant workforce. While a wide and varying range of services are offered, the majority focus on chronic disease management, pulmonary rehabilitation, oxygen therapy and advanced disease care. The Results from this survey will be used by the BTS MoCC to create a directory of integrated respiratory services as a resource for the respiratory community. 